\title{
Hydroxyurea induces fetal \\ hemoglobin by the nitric \\ oxide-dependent activation \\ of soluble guanylyl cyclase
}

\author{
Vladan P. Cokic, ${ }^{1,2}$ Reginald D. Smith, ${ }^{1}$ Bojana B. Beleslin-Cokic, ${ }^{1}$ Joyce M. Njoroge, ${ }^{1}$ \\ Jeffery L. Miller, ${ }^{1}$ Mark T. Gladwin, ${ }^{1,3}$ and Alan N. Schechter ${ }^{1}$ \\ ${ }^{1}$ Laboratory of Chemical Biology, National Institute of Diabetes and Digestive and Kidney Diseases, \\ National Institutes of Health, Bethesda, Maryland, USA \\ ${ }^{2}$ Institute for Medical Research, Belgrade, Yugoslavia \\ ${ }^{3}$ Critical Care Medicine Department, Clinical Center, National Institutes of Health, Bethesda, Maryland, USA
}

\begin{abstract}
Hydroxyurea treatment of patients with sickle-cell disease increases fetal hemoglobin (HbF), which reduces hemoglobin S polymerization and clinical complications. Despite its use in the treatment of myeloproliferative diseases for over 30 years, its mechanism of action remains uncertain. Recent studies have demonstrated that hydroxyurea generates the nitric oxide (NO) radical in vivo, and we therefore hypothesized that NO-donor properties might determine the hemoglobin phenotype. We treated both K562 erythroleukemic cells and human erythroid progenitor cells with S-nitrosocysteine (CysNO), an NO donor, and found similar dose- and time-dependent induction of $\gamma$-globin mRNA and $\mathrm{HbF}$ protein as we observed with hydroxyurea. Both hydroxyurea and CysNO increased cGMP levels, and the guanylyl cyclase inhibitors ODQ, NS 2028, and LY 83,538 abolished both the hydroxyurea- and CysNO-induced $\gamma$-globin expression. These data provide strong evidence for an NOderived mechanism for $\mathrm{HbF}$ induction by hydroxyurea and suggest possibilities for therapies based on NO-releasing or -potentiating agents.
\end{abstract}

J. Clin. Invest. 111:231-239 (2003). doi:10.1172/JCI200316672.

\section{Introduction}

Hydroxyurea, which has long been used to treat myeloproliferative diseases, reduces the rates of vaso-occlusive crisis, acute chest syndrome, and transfusion requirement in patients with sickle-cell disease $(1,2)$. The mechanism of the salutary effect of hydroxyurea is largely attributable to its ability to increase fetal hemoglobin $(\mathrm{HbF})$ levels, thereby altering the kinetics and thermodynamics of hemoglobin S polymerization (3). Hydroxyurea administration augments $\mathrm{HbF}$ production and inhibits in vitro growth of erythroid

Received for publication August 15, 2002, and accepted in revised form October 16, 2002.

Address correspondence to: Alan N. Schechter,

Laboratory of Chemical Biology, National Institute of Diabetes and Digestive and Kidney Disease, National Institutes of Health, 9000 Rockville Pike, Building 10, Room 9N307, Bethesda, Maryland 20892-1822, USA. Phone: (301) 496-5408;

Fax: (301) 402-0101; E-mail: aschecht@helix.nih.gov.

Conflict of interest: The authors have declared that no conflict of interest exists.

Nonstandard abbreviations used: fetal hemoglobin ( $\mathrm{HbF}$ );

$\mathrm{S}$-nitrosocysteine (CysNO); soluble guanylyl cyclase (sGC);

(Z)-1-[N-(2-aminoethyl)-N-(2-ammonioethyl)amino]diazen-1ium-1,2-diolate (DETA-NONOate); stem cell factor (SCF); $1 \mathrm{H}-[1,2,4]$ oxadiazolo[4,3-a]quinoxalin-1-one (ODQ); 4H-8-bromo-1,2,4-oxadiazolo[3,4-d]benz[b](1,4)oxazin-1-one (NS 2028); 6-(phenylamino)-5,8-quinolinedione, 6-anilino-5,8quinolinedione (LY-83,583); sodium $(\mathrm{Z})-1-(\mathrm{N}, \mathrm{N}-$

diethylamino)diazen-1-ium-1,2-diolate (DEA-NONOate); adult hemoglobin ( $\mathrm{HbA}$ ); nitrosyl hemoglobin ( $\mathrm{HbNO}$ ); activator protein 1 (AP-1); MAPK kinase (MEK). colonies from the blood of anemic nonhuman primates (4) and patients with sickle-cell anemia $(5,6)$. In vitro, hydroxyurea can raise $\gamma$-globin levels by acting on early progenitors (7) as well as by interacting directly with late erythroid precursors that are already engaged in hemoglobin production (8). Hydroxyurea increases total intracellular hemoglobin (9) in the human K562 erythroleukemia cell line and preferentially increases G $\gamma$-globin mRNA levels in these cells (10). In two-phase mixed cultures of peripheral-blood mononuclear and erythroid progenitor cells from normal donors, hydroxyurea significantly increases both $\gamma$-globin mRNA levels and $\mathrm{HbF}$ and also has a comparatively small stimulatory effect on $\beta$-globin mRNA expression (11). After it was shown that hydroxyurea inhibited DNA synthesis (12), perhaps accounting for its cytostatic effects, ribonucleotide reductase was identified as a target enzyme of hydroxyurea in a cell-free bacterial system (13), but the detailed mechanism of action of hydroxyurea remains uncertain.

Recently it has been shown that hydroxyurea can be oxidized by heme groups to produce the free-radical gas molecule NO in vitro (14-16) as well as in vivo (17-19). We recently measured plasma and red cell NO reaction products - nitrate, nitrite, and nitrosylated hemoglobin - by ozone-based chemiluminescence assays in 19 patients with sickle-cell disease and found that levels of these NO-derived species increased significantly after an oral dose of hydroxyurea, consistent 
with NO release from hydroxyurea in vivo (20). One potential mechanism by which hydroxyurea induces $\mathrm{HbF}$ has been hypothesized to involve the redox inactivation of a tyrosyl radical on ribonucleotide reductase $(21,22)$, an effect that can be mediated by $\mathrm{NO}(23$, $24)$ and nitrovasodilators (25). Furthermore, Ikuta and colleagues (26) recently demonstrated that soluble guanylyl cyclase (sGC) activators or analogs increased $\gamma$-globin gene expression in erythroleukemic cells and in primary human erythroblasts and that the activity of hemin and butyrate on $\gamma$-globin induction was prevented by inhibiting sGC or cGMP-dependent protein kinase. These basic observations provide a strong argument for the participation of $\mathrm{NO}$ in the mechanism of $\mathrm{HbF}$ induction by hydroxyurea. Consistent with this thesis, we now show that increases in $\gamma$-globin gene and protein expression correlate strongly with NO-radical donation by hydroxyurea acting through the sGC/cGMP pathway.

\section{Methods}

Synthesis of S-nitrosocysteine. S-nitrosocysteine (CysNO) was prepared by reaction of acidified L-cysteine with nitrite $\left(\mathrm{NaNO}_{2}\right)$ and then neutralized to $\mathrm{pH} 7.4$ using 5 $\mathrm{N} \mathrm{NaOH}$. A molar concentration was determined by spectrophotometry $\left(\varepsilon_{\lambda 335}=503 \mathrm{~mol} / \mathrm{l}\right)$ of $\mathrm{CysNO}$ aliquots diluted in EDTA water. All chemicals were obtained from Sigma-Aldrich (St. Louis, Missouri, USA). K562 cell cultures. Human erythroleukemic K562 cells were cultured in six-well plates at $37^{\circ} \mathrm{C}$ in suspension in RPMI-1640 medium (Biofluids, Gaithersburg, Maryland, USA) with 10\% FBS (Gemini BioProducts, Woodland, California, USA), $100 \mathrm{U} / \mathrm{ml}$ penicillin, $100 \mu \mathrm{g} / \mathrm{ml}$ streptomycin, and $2 \mathrm{mmol} / \mathrm{l}$ glutamine (Biofluids). K562 cells $\left(10^{6}\right)$ were incubated for 24 hours with hydroxyurea (Sigma-Aldrich) and the NO donors CysNO and (Z)-1[N-(2-aminoethyl)-N-(2-ammonioethyl)amino]diazen1-ium-1,2-diolate (DETA-NONOate; Alexis Biochemicals, San Diego, California, USA). After incubation and isolation of RNA, $\gamma$-globin gene expression was measured in femtomoles per $10^{6}$ cells. The viable cell counts were performed with the use of a trypan-blue exclusion technique (BioWhittaker, Walkersville, Maryland, USA).

Two-phase liquid erythroid cell cultures. Peripheral-blood mononuclear cells were isolated from buffy coats ( $n=3-6$ individuals per experiment) of normal donors using Lymphocyte Separation Medium (BioWhittaker). We extended a two-phase liquid culture protocol previously described by Fibach (27). We washed mononuclear cells twice with Dulbecco's PBS (Invitrogen Corp., Grand Island, New York, USA) and resuspended them in liquid culture containing MEM Eagle (Sigma-Aldrich) supplemented with 10\% FBS, $1 \mu \mathrm{g} / \mathrm{ml}$ cyclosporin A (Sigma-Aldrich), $100 \mathrm{U} / \mathrm{ml}$ penicillin, $100 \mu \mathrm{g} / \mathrm{ml}$ streptomycin, $2 \mathrm{mmol} / \mathrm{l}$ glutamine, and $10 \%$ conditioned medium obtained from cultures of the 5637 human bladder carcinoma cell line (American Type Culture Collection, Manassas, Virginia, USA). After 7 days of incubation at $37^{\circ} \mathrm{C}\left(5 \% \mathrm{CO}_{2}, 95 \%\right.$ humidity) in phase I culture, the nonadherent cells were harvested by centrifugation and washed once in $\mathrm{PBS}$, and the CD34+ cells were purified using the StemSep Cell Separation method (Stem Cell Technologies Inc., Vancouver, Canada). The unlabeled desired cells $\left(\mathrm{CD} 34^{+}\right)$were collected in the column flowthrough and resuspended in the phase II medium. The phase II medium contained $30 \% \mathrm{FBS}, 2 \mathrm{mmol} / \mathrm{l}$ glutamine, 100 $\mathrm{U} / \mathrm{ml}$ penicillin, $100 \mu \mathrm{g} / \mathrm{ml}$ streptomycin, $1 \%$ deionized BSA, $10 \mu \mathrm{mol} / 1 \beta$-mercaptoethanol, $1 \mu \mathrm{mol} / 1$ dexamethasone, $33 \mu \mathrm{g} / \mathrm{ml}$ holo-transferrin, $10 \mathrm{ng} / \mathrm{ml}$ stem cell factor (SCF), $1 \mathrm{ng} / \mathrm{ml} \mathrm{IL-3,} 1 \mathrm{ng} / \mathrm{ml}$ GM-CSF (SigmaAldrich), and $1 \mathrm{U} / \mathrm{ml}$ human recombinant erythropoietin (Amgen Inc., Thousand Oaks, California, USA).

Erythroid progenitor cells were treated with CysNO on day 3 or 5 after initiation of phase II cultures and incubated for 24 hours at $37^{\circ} \mathrm{C}$ in a humidified atmosphere with $5 \% \mathrm{CO}_{2}$. On day 4 , we treated them with hydroxyurea, and total RNA was isolated 48 hours after exposure to the drug. Before exposure to the drug in the experiments with selective inhibitors of sGC, the preincubation period was 30 minutes with $1 \mathrm{H}-[1,2,4]$ oxadiazolo[4,3-a]quinoxalin-1-one (ODQ; Sigma-Aldrich), 15 minutes with 4H-8-bromo-1,2,4oxadiazolo[3,4-d]benz[b](1,4)oxazin-1-one (NS 2028), and 12 hours with 6-(phenylamino)-5,8-quinolinedione; 6-anilino-5,8-quinolinedione (LY-83,583; Alexis). Gene expression of $\gamma$ - and $\beta$-globin was measured in femtomoles per number of cells. However, because of the variations in mRNA levels from cell culture to culture, the values for cells treated with one of the agents (with or without inhibitors) are expressed as fold changes relative to the appropriate control.

Flow cytometry. At different time points during erythroid differentiation of $\mathrm{CD} 34^{+}$cells, the expression of surface markers was evaluated for 14 days in phase II medium. Cells were treated with hydroxyurea and CysNO on day 1 and day 3, respectively. Immunofluorescence staining was performed by adding $10 \mu \mathrm{l}$ of phycoerythrin-conjugated mouse antihuman CD34 and glycophorin A antibodies (Beckman-Coulter, Miami, Florida, USA) to $2 \times 10^{5}$ cells and incubated for 30 minutes at $4^{\circ} \mathrm{C}$ in the dark. After incubation, cells were washed twice and resuspended in cold PBS. Flow cytometry was performed with an Epics Elite flow cytometer (Coulter, Hialeah, Florida, USA) equipped with an air-cooled argon laser at $488 \mathrm{~nm}$. Stained cells were scored as positive if their fluorescence was measured at levels at least two standard deviations above the negative control.

Erythroid cells containing hemoglobin were detected by specific reaction with a hydrogen peroxide/benzidine solution (ratio 1:50) prepared just before the assay. The proportion of benzidine-positive cells was determined using an inverted microscope.

Isolation of total RNA. For isolation of total RNA from CD34+ and erythroid cells we used RNeasy Kit (Qiagen, Valencia, California, USA) according to the manufacturer's instructions. The concentration and integrity of 
total RNA were assessed using an $8453 \mathrm{UV} /$ Visible Spectrophotometer (Hewlett-Packard GmbH, Waldbronn, Germany) and Agilent 2100 Bioanalyzer Software (Agilent Technologies, Waldbronn, Germany). One microgram of total RNA was reverse transcribed with SuperScript II RNase $\mathrm{H}^{-}$Reverse Transcriptase kit (Invitrogen Corp., Carlsbad, California, USA).

Quantitative PCR. Quantitative real-time PCR assay of $\gamma$-and $\beta$-globin mRNA transcripts was carried out with the use of gene-specific double-fluorescently labeled probes in a 7700 Sequence Detector (Applied Biosystems, Foster City, California, USA). The specific primers and TAQMAN probes (synthesized by the NIDDK core oligonucleotide facility) were designed using Primer Express software and prepared on an ABI 394 synthesizer as previously described (11). Platinum Quantitative PCR SuperMix-UDG (Invitrogen Corp., Carlsbad, California, USA) was used for each of the primer pairs containing a final concentration of $200 \mu \mathrm{M} 2$ '-deoxynucleoside 5 '-triphosphates (dNTPs is a mix of dATP, dCTP, dGTP, and dTTP), $0.5 \mu \mathrm{M}$ Rox reference dye (Invitrogen Corp., Carlsbad, California, USA), $0.2 \mu \mathrm{M}$ each of TAQMAN probe, forward and reverse primers. Expression levels were determined using the associated SDS software (ABI Prism; Applied Biosystems) and Microsoft Excel.

High-performance liquid chromatography. Erythroid cells were treated on day 4 of cell culture either with CysNO $(100 \mu \mathrm{M})$ or hydroxyurea $(30 \mu \mathrm{M})$ and harvested at different time points during their differentiation. To perform HPLC quantitation of hemoglobin, we separated hemoglobins by cation-exchange HPLC of supernatants from cell lysates. The pelleted cells were resuspended, lysed in sterile distilled water, and centrifuged in $0.45 \mu \mathrm{m}$ of filter unit (Millipore Corp., Bedford, Massachusetts, USA) for 10 minutes at $4^{\circ} \mathrm{C}$. The filtrate was chromatographed on a PolyCAT A $20 \times 4.0 \mathrm{~mm}$ column (PolyLC Inc., Columbia, Maryland, USA) fitted to a Gilson HPLC (Gilson Inc., Middleton, Wisconsin, USA) developed with a sodium chloride gradient in $20 \mathrm{mmol} / \mathrm{l}$ BisTris buffer ( $\mathrm{pH}$ 6.55-6.96). Peak areas were integrated with the use of the system software.
cGMP immunoassay. Erythroid cells were grown in phase II medium at $37^{\circ} \mathrm{C}$ in a humidified atmosphere with $5 \% \mathrm{CO}_{2}$ and treated with hydroxyurea or CysNO on day 4 of culture, and about $10^{6}$ cells were harvested on day 6. Cells were pretreated for 30 minutes with 3-isobutyl-1-methylxanthine (Sigma-Aldrich) at a final concentration of $0.5 \mathrm{mM}$ to inhibit phosphodiesterase activity. cGMP levels were measured using the cGMP immunoassay (R\&D Systems Inc., Minneapolis, Minnesota, USA) according to the protocol of the supplier.

Statistical analysis. The one way ANOVA and Dunnett's post test were applied using Prism 3 software (GraphPad Software Inc., San Diego, California, USA).

\section{Results}

Hydroxyurea and NO donors increase $\gamma$-globin levels in K562 cells. In order to establish whether NO participates in $\gamma$ globin expression, we studied the effects of NO donors on the K562 erythroleukemic cell line and compared the responses to those of hydroxyurea. We used quantitative real-time PCR to measure the effects of increasing doses of hydroxyurea and two NO donors, CysNO $\left(t_{1 / 2}=30\right.$ minutes $)$ and DETA-NONOate $\left(t_{1 / 2}=20\right.$ hours) on $\gamma$-globin mRNA in these cells (Figure 1). We found that all of these compounds increased $\gamma$-globin gene expression in a dose-dependent manner in concentrations up to $200 \mu \mathrm{M}$. However, at concentrations of $100-200 \mu \mathrm{M}$, we found that these compounds caused a $20-30 \%$ decrease in cell numbers after 24 hours of incubation. Thus, we express our results in femtomoles of $\gamma$-globin mRNA per $10^{6}$ cells to obtain estimates of the effects of those compounds on the phenotype of these cells. Hydroxyurea (Figure 1a), CysNO (Figure 1b), and DETA-NONOate (Figure 1c) all dose-dependently increased $\gamma$-globin gene expression and increased levels between 2- and 4-fold at a concentration of $200 \mu \mathrm{M}$. Since $200 \mu \mathrm{M}$ DETA-NONOate releases $400 \mu \mathrm{M}$ NO with a half-life of 20 hours at $37^{\circ} \mathrm{C}$, NO delivery from these two donors would be comparable during the experiment.

Erythroid differentiation of $\mathrm{CD} 34^{+}$cells. Phase II medium contains a cocktail of cytokines that favor erythroid differentiation of purified CD $34^{+}$cells. We used different
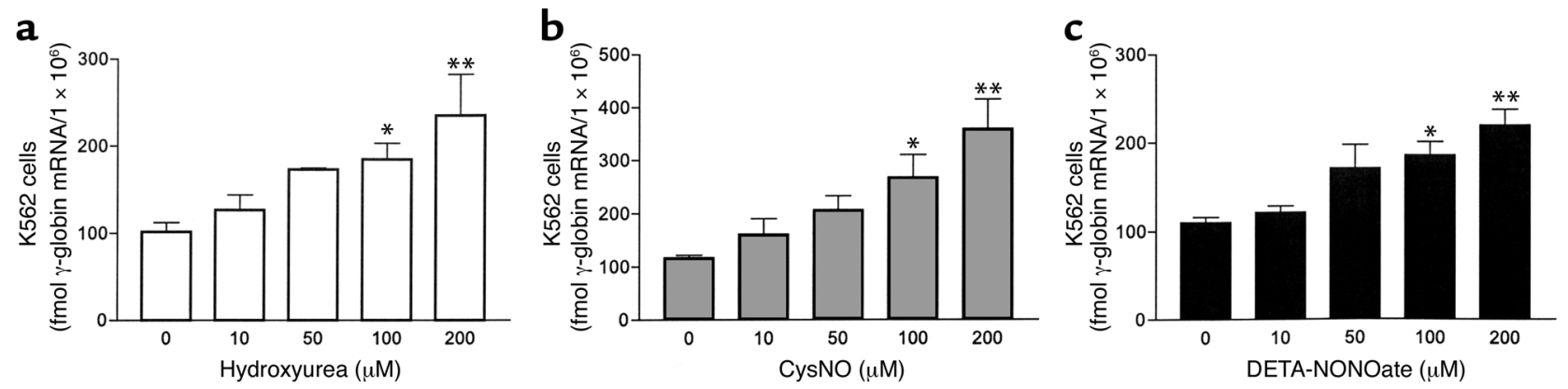

Figure 1

Hydroxyurea and NO induce $\gamma$-globin gene expression in K562 cells. (a-c) Hydroxyurea (white bars), CysNO (gray bars), and DETA-NONOate (black bars) induce $\gamma$-globin gene expression in K562 cells measured as femtomoles of $\gamma$-globin mRNA per $10^{6}$ cells after 24 hours of treatment. Values represent means $\pm \operatorname{SEM}(n=3)$. ${ }^{*} P<0.05$ and ${ }^{* *} P<0.01$ versus untreated cells $(0)$. 


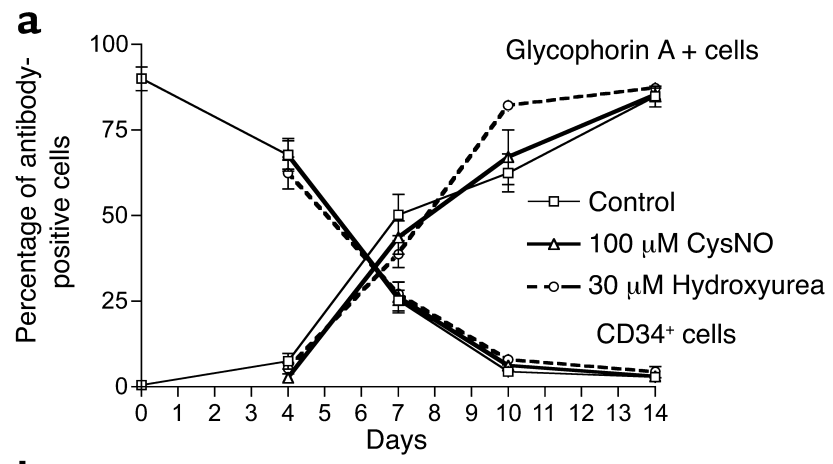

b
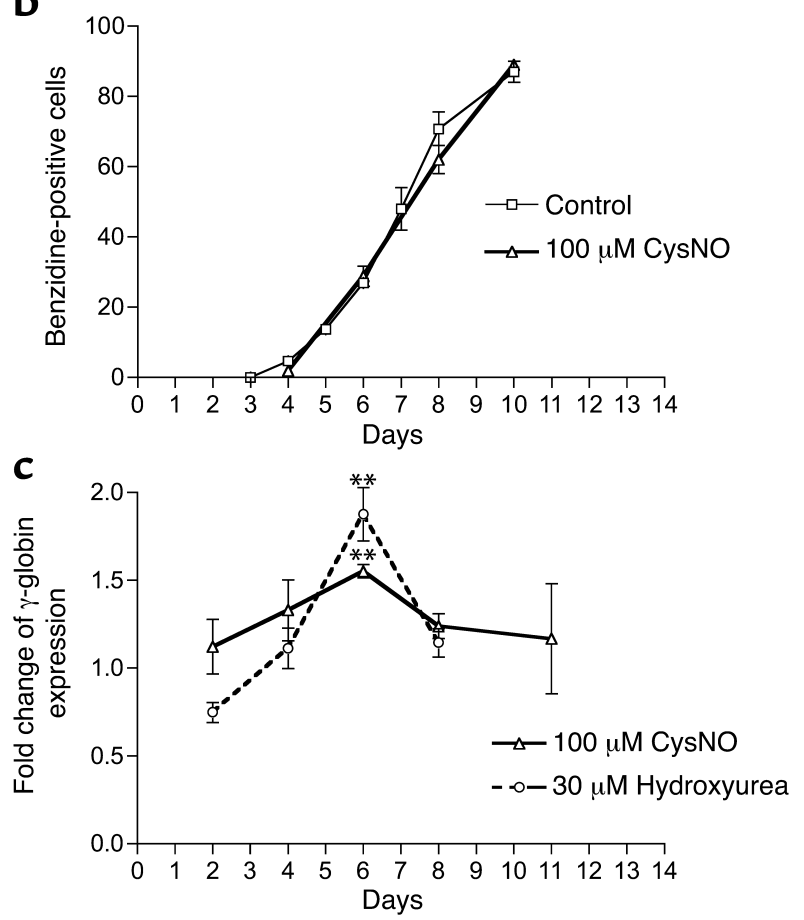

antibodies to characterize our liquid cell cultures (Figure 2). CD34 antigen density is highest on hematopoietic/erythroid progenitor cells (on day $0,90 \%$; on day 4 , $60-70 \%$ ) and decreases as cells mature (on day 10, 4\%). Glycophorin A, the marker of erythroid precursor cells and red blood cells, rises from about $5 \%$ on day 4 (on day $0,0-1 \%$ ) to about $90 \%$ on day 14 (cell pellet is red or reddish on day 10). CD71 antigen (transferrin receptor) is also present on early erythroid cells (about 90\% between days 4 and 7) but declines during maturation (data not shown). Another marker of early erythroid cells, CD36, rises from day 4 with a plateau between

\section{Figure 3}

Hydroxyurea induces $\gamma$-globin gene expression in erythroid progenitor cells. ( $\mathbf{a}$ and $\mathbf{b}$ ) Hydroxyurea induces $\gamma$-globin gene expression (a) and increases the $\gamma / \beta$ ratio (b) in erythroid progenitor cells. Erythroid progenitor cells were treated with hydroxyurea on day 4 , and after 48 hours of incubation total RNA was isolated. Data are normalized by cell number and, for each culture experiment, are expressed as ratios to values for controls not treated with hydroxyurea. Values represent means $\pm \operatorname{SEM}(n=4)$. ${ }^{*} P<0.05$ and ${ }^{*} P<0.01$ versus untreated cells $(0)$.

\section{Figure 2}

Flow cytometry of erythroid cells during their differentiation. (a) We used glycophorin A and CD34 antibodies to detect changes in the percentage of antibody-positive cells during erythroid differentiation of $\mathrm{CD}_{34}{ }^{+}$cells. Hydroxyurea and Cys NO did not influence erythroid differentiation ( $n=5$ or 6 ). (b) After 24 hours of incubation with 100 $\mu \mathrm{M}$ Cys $\mathrm{NO}$ at different time points of erythroid differentiation, the benzidine-positive cells were scored and expressed as a percentage of the number of total cells $(n=3)$. (c) At different time points during erythroid differentiation, after 24 hours of incubation with hydroxyurea or CysNO, we harvested erythroid cells (corresponding to values for days in the figure) and compared induction of $\gamma$-globin mRNA expression. Data are normalized by cell number and, for each culture experiment, are expressed as ratios to values for controls not treated with hydroxyurea or CysNO. Values represent means $\pm \operatorname{SEM}(n=3$ or 4). ${ }^{*} P<0.01$ versus control.

days 7 and 10 (data not shown). Hydroxyurea and CysNO did not have a statistically significant influence on the percentage of either $\mathrm{CD} 34$ or glycophorin $\mathrm{A}$ antibody-positive erythroid cells (Figure 2a). In this cell culture system, the percentage of benzidine-positive cells increases gradually during erythroid maturation. CysNO does not change the rate of differentiation (Figure 2b), nor does hydroxyurea treatment, as previously described (8). The maximum fold change of $\gamma$-globin mRNA expression induced by hydroxyurea and CysNO occurs concomitantly with switching from CD34-positive cells to glycophorin A-positive cells (Figure 2c).

Hydroxyurea induces $\gamma$-globin expression in human erythroid progenitor cells. We tested the effects of hydroxyurea and NO-donor compounds in the more physiologically relevant two-phase liquid culture system of purified erythroid cells from normal donors. CD34 ${ }^{+}$ cells grown and isolated (phase I), as described, from human peripheral blood were then grown in a cytokine mixture including erythropoietin (phase II medium) which favors erythroid differentiation. Absolute

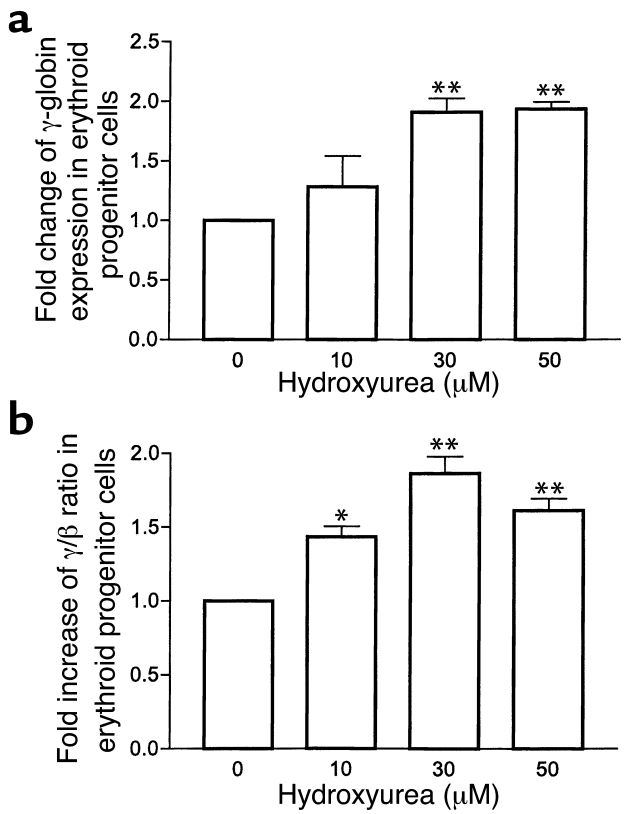


mRNA levels vary significantly from culture to culture, although values of $\gamma$-globin mRNA tended to range from about $6 \mathrm{fmol}$ on day 2 to $25 \mathrm{fmol}$ per $10^{5}$ cells on day 8 . Thus, we express our results for each culture relative to control cells. In addition, hydroxyurea inhibits moderate proliferation of these erythroid cells; for example, $50 \mu \mathrm{M}$ hydroxyurea added on day 4 inhibits growth as measured on day 6 by $35-40 \%$. At higher concentrations of hydroxyurea, inhibition of cell growth was more pronounced.

When we measure $\gamma$-globin expression per microgram of mRNA, $30 \mu \mathrm{M}$ of hydroxyurea added on day 4 induces a 1.7-fold increase when mRNA is measured on day 6 (data not shown). When induction is expressed per cell, it is found to be dose dependent, with a maximum increase of about 2-fold at $30 \mu \mathrm{M}$ (Figure 3a). Hydroxyurea induces a similar increase in the $\gamma / \beta$ ratio (important as a likely measure of potential therapeutic benefit), because in this range hydroxyurea has little effect on $\beta$-globin gene expression (Figure $3 b$ ). After 24 hours of treatment, when the drug was added on day 5 , hydroxyurea induces a very similar fold increase in $\gamma$-globin expression (Figure 2c). The effects of adding hydroxyurea earlier or later to the cultures were generally smaller than the effects seen on days 4-6. Exclusion of all other added cytokines except erythropoietin, SCF, and IL-3 from cells grown in the presence of serum and hydroxyurea did not significantly change the increase in $\gamma$-globin expression (data not shown).

NO donors induce $\gamma$-globin expression in human erythroid progenitor cells. CysNO showed both a dose-dependent and a time-dependent induction of $\gamma$-globin expression in primary erythroid progenitor cells similar to that of hydroxyurea (Figure 4). At different time points during erythroid differentiation, $\mathrm{CD} 34^{+}$cells, purified from peripheral blood of normal donors, were treated for 24 hours with CysNO. Cysteine alone at these concentrations did not have an effect on $\gamma$-globin expression or proliferation of these erythroid cells (data not shown). On day 3 of erythroid cell culture, CysNO increases $\gamma$-globin expression 1.8-fold (Figure $4 a$ ) with a maximum at about $10 \mu \mathrm{M}$ but without significant changes in the $\gamma / \beta$ ratio because of a similar change in $\beta$-globin gene expression. On day 5 of culture, the effect of CysNO on $\gamma$-globin expression is shifted to higher concentrations; a 1.6-fold maximum increase at $100 \mu \mathrm{M}$ (Figure $4 \mathrm{~b}$ ) and, in addition, a strong effect on the $\gamma / \beta$ ratio were observed (Figure 4c), due to the fact that $\beta$-globin levels did not change. On day 7, two other NO donors - sodium(Z)-1-(N,N-diethylamino)diazen-1ium-1,2-diolate (DEA-NONOate) and DETA NONOate - induced both $\beta$ - and $\gamma$-globin expression about 2 -fold when measured on day 8; however, the effect of CysNO was less at that point. Statistically significant inhibition of cell proliferation is observed at concentrations of 100 $\mu \mathrm{M}$ or higher of CysNO when added on day 3 or 5 , but during later or terminal maturation of erythroid cells that inhibition is diminished (data not shown). Reduced inhibition of cell proliferation by CysNO overlaps with an increase in the levels of total hemoglobin (data not shown) and benzidine-positive cells during maturation of erythroid cells (Figure 2b). We believe the progressive resistance to CysNO is secondary to erythroid maturation and increasing intracellular hemoglobin, which scavenges NO.

HbF induction in human erythroid cells. To test whether these observed effects on mRNA levels manifested as changes in the levels of $\mathrm{HbF}$, we measured the latter using cation-exchange HPLC. During erythroid differentiation, $\mathrm{CD} 34^{+}$cells (grown from peripheral blood) were treated on day 4 either with hydroxyurea $(30 \mu \mathrm{M})$ or CysNO $(100 \mu \mathrm{M})$; HPLC analysis was subsequently done to quantitate the human hemoglobins expressed in these cells (levels of about $5 \% \mathrm{HbF}$ in the control cells) (Figure 5a). Hydroxyurea and CysNO both caused a monotonic increase in $\mathrm{HbF}$, as compared with

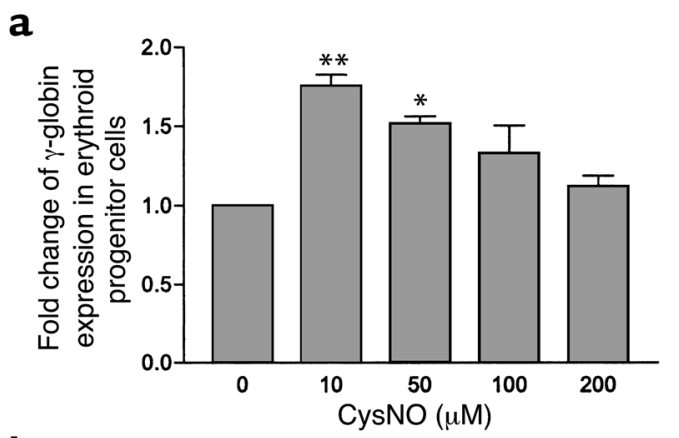

b

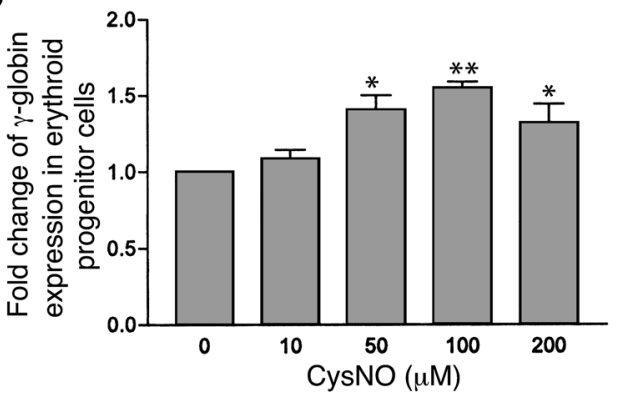

C

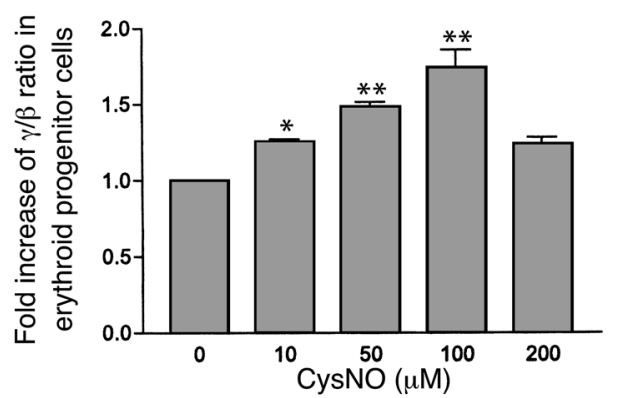

\section{Figure 4}

CysNO induces $\gamma$-globin gene expression in erythroid progenitor cells. (a) We treated erythroid progenitor cells with CysNO on day 3, and after 24 hours of incubation we harvested them and measured $\gamma$-globin expression $(n=3)$. (b and $\mathbf{c}$ ) On day 5 of erythroid cell culture, we added CysNO, and we measured mRNA levels on day 6; CysNO increases $\gamma$-globin expression (normalized as in Figure 3) (b) as well as the $\gamma / \beta$ ratio $(\mathbf{c})$. Values represent means $\pm \operatorname{SEM}(n=4)$. ${ }^{*} P<0.05$ and ${ }^{*} P<0.01$ versus untreated cells $(0)$. 
$\mathbf{a}$
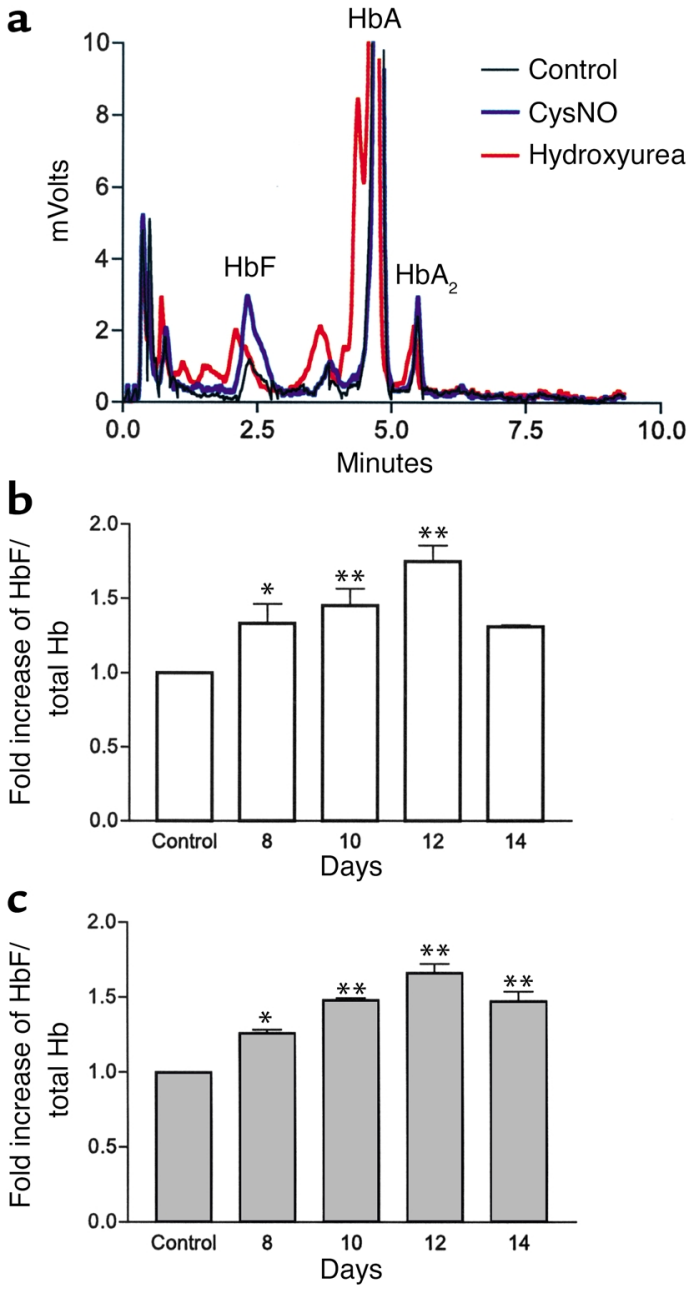

control cells, during subsequent growth in culture, with about a 1.7 -fold increase observed on day 12 (Figure $5, \mathrm{~b}$ and c). Hydroxyurea and $\mathrm{CysNO}$ also increased the level of several minor globin peaks between $\mathrm{HbF}$ and adult hemoglobin (HbA). Hydroxyurea resulted in a new peak, joined to $\mathrm{HbA}$ (Figure 5a); the appearance of this species due to carbamylated hemoglobin in uremic patients has been reported previously $(28,29)$.

\section{Figure 5}

HPLC analysis of changes in HbF during maturation of erythroid cells. On day 4 of erythroid cell culture, we treated erythroid progenitor cells either with hydroxyurea (white bars) or Cys NO (gray bars) and measured $\mathrm{HbF}$ versus total hemoglobin levels at different time points during erythroid maturation. (a) Chromatograms of HPLC analyses of hemoglobins produced by erythroid precursor cells during treatment with hydroxyurea $(30 \mu \mathrm{M}$, red line) and Cys NO ( $100 \mu \mathrm{M}$, blue line) on day 10 . ( $\mathbf{b}$ and $\mathbf{c}$ ) Increases in the percent of $\mathrm{HbF}$ to total hemoglobin after treatment with $30 \mu \mathrm{M}$ hydroxyurea (b) and $100 \mu \mathrm{M}$ Cys NO (c). Values represent means $\pm \operatorname{SEM}(n=4)$. ${ }^{*} P<0.05$ and ${ }^{*} P<0.01$ versus control.

Hydroxyurea and CysNO increase cGMP levels in erythroid progenitor cells. Although it is known that NO donors can increase intracellular cGMP levels in human bone marrow mononuclear cells (30), such an NO-dependent signaling effect has not been shown for hydroxyurea. We used an immunoassay to test if these inducers of $\gamma$-globin mRNA and $\mathrm{HbF}$ acted through the NO-dependent cGMP pathway. Hydroxyurea or CysNO were added on day 4, and cGMP levels were measured in the human erythroid progenitor cells on day 6 - that is, after 48 hours of incubation. Hydroxyurea showed a dosedependent induction of cGMP with a peak at $30 \mu \mathrm{M}$, and induction occurred from a baseline of about 10 to a value of $65 \mathrm{fmol}$ per $10^{5}$ cells (Figure 6a). CysNO (50 $\mu \mathrm{M})$ also increased cGMP levels when measured after 48 hours, but levels at that time were about half the magnitude of hydroxyurea (Figure 6c). However, as expected, immediately after adding CysNO there was a tremendous increase in cGMP levels (to about 3000 fmol per $10^{5}$ cells) that began to taper after 4 hours, whereas the effects of hydroxyurea $(30 \mu \mathrm{M})$ remained elevated for several days (Figure 6, b and c). Different pharmacological NO profiles from these drugs explain differing cGMP responses.

$\gamma$-Globin gene induction is inbibited by sGC inbibitors. On day 6 , after 48 hours of incubation with hydroxyurea $(30 \mu \mathrm{M})$ and pretreatment with three selective sGC inhibitors - ODQ $(10 \mu \mathrm{M})$, NS $2028(0.5 \mu \mathrm{M})$, and LY-83,538 (5 $\mu \mathrm{M})$ - we found that each separately a

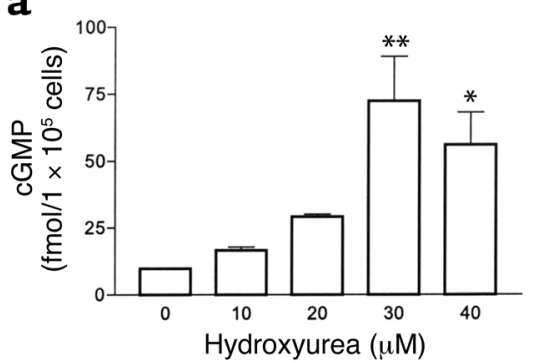

b

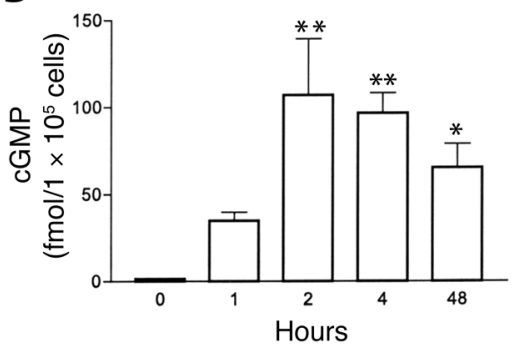

c

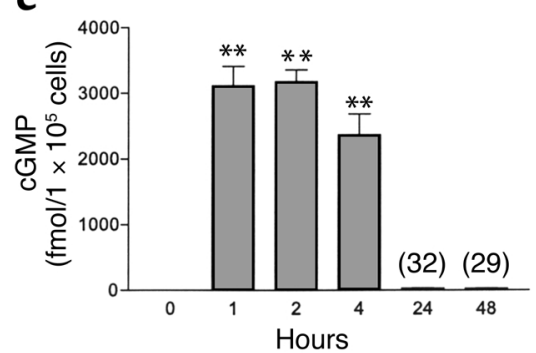

Figure 6

Effects of hydroxyurea and CysNO on intracellular cGMP levels in erythroid progenitor cells. (a) Hydroxyurea (white bars) was added on day 4 to a suspension of erythroid progenitor cells, and intracellular cGMP levels were measured after 48 hours. (b) Hydroxyurea (30 $\mu$ M) was added on day 4, and cGMP levels were measured within the first 4 hours, as well as after 48 hours. (c) CysNO (100 $\mu \mathrm{M}$, gray bars) was added on day 4 , with measurements taken for the first 4 hours as well as after 24 and 48 hours. Values represent means \pm SEM $(n=3)$. ${ }^{*} P<0.05$ and ${ }^{*} P<0.01$ versus untreated cells $(0)$. 


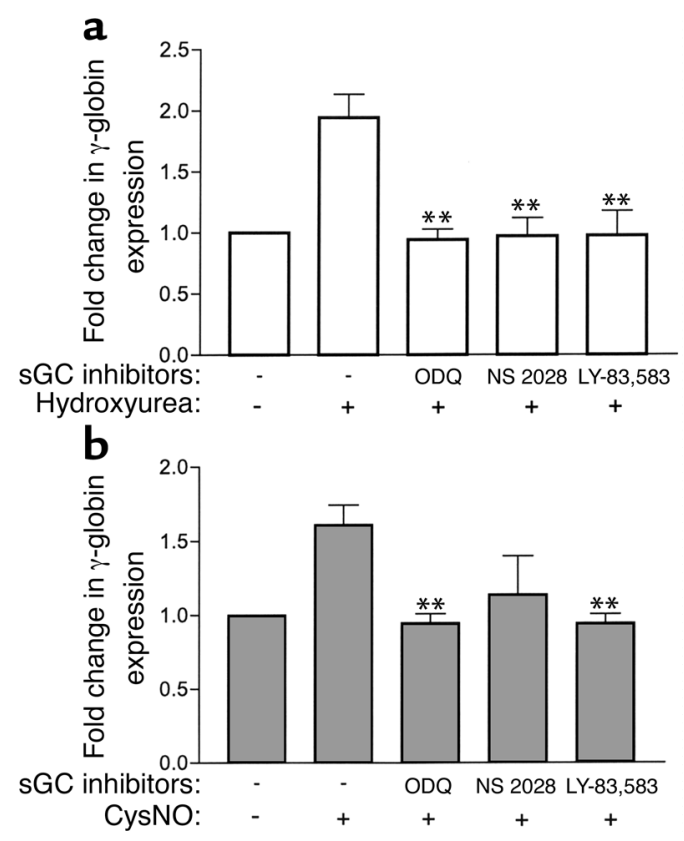

Figure 7

Inhibition of $\gamma$-globin induction by sGC inhibitors. (a) Before incubation with hydroxyurea $(30 \mu \mathrm{M})$, erythroid progenitor cells were pretreated with the SGC inhibitors ODQ $(10 \mu \mathrm{M})$, NS $2028(0.5$ $\mu \mathrm{M})$, and $\mathrm{LY} 83,583(5 \mu \mathrm{M})$ for 30 minutes, 15 minutes, and 12 hours, respectively. Hydroxyurea (white bars) was added on day 4, and $\gamma$-globin mRNA levels were measured after 48 hours. (b) After preincubation with sGC inhibitors (as for preincubation for hydroxyurea), erythroid progenitor cells were treated with CysNO (100 $\mu \mathrm{M}$, gray bars) on day 5 , and $\gamma$-globin mRNA levels were measured after 24 hours. Values represent means $\pm \operatorname{SEM}(n=3)$. ${ }^{*} P<0.01$ versus cells treated with hydroxyurea or Cys NO.

reduce hydroxyurea-induced $\gamma$-globin expression to the control level in erythroid progenitor cell culture (Figure $7 \mathrm{a})$. On day 6 , after 24 hours of incubation with CysNO $(100 \mu \mathrm{M})$, these three sGC inhibitors also separately inhibited $\gamma$-globin expression induced by CysNO to baseline values (Figure $7 \mathrm{~b}$ ). These data suggest that the effects of hydroxyurea on $\gamma$-globin gene expression are completely dependent on sGC in our system. These data also cast doubt on a significant role for ribonucleotide reductase inhibition in the mechanism of fetal hemoglobin expression, although participation of this enzyme in other steps in erythroid progenitor cell differentiation cannot be excluded.

\section{Discussion}

We found that, like hydroxyurea, several NO donors induce $\gamma$-globin mRNA expression in human erythroleukemic K562 cells and erythroid progenitor cells in two-phase liquid erythroid cultures. Incubation of these erythroid cells with either hydroxyurea or CysNO also increases levels of $\mathrm{HbF}$ protein. We observed an increase of cGMP levels in the erythroid progenitor cells after treatment with CysNO, an NO donor with a half-life of about 30 minutes. Hydroxyurea induces a much smaller increase of cGMP levels than CysNO, but that stimulation lasted during the 48 hours of treatment, as compared with the very short effect (a few hours) of CysNO. $\gamma$-Globin induction by both hydroxyurea and CysNO was prevented by sGC inhibitors.

In our experiments, a narrow window of hydroxyurea and NO-donor induction of $\gamma$-globin expression is concomitant with decreased levels of CD34 surface markers but still elevated levels of CD71 surface markers, which are markers for erythroid progenitor cells. However, the ability to induce $\mathrm{HbF}$ is reduced on full erythroid maturation, an effect that is most likely secondary to reduced gene expression with pyknosis of the nuclei and the increase in intracellular hemoglobin, which is a potent NO scavenger. This occurs because NO reacts with oxyhemoglobin by dioxygenation to form the inactive nitrate (20). These results indicate that drug effects occur during only a fraction of the cell-maturation time and probably slow down the overall biological response, since only cells at a certain developmental stage would be expected to respond.

Induction of $\mathrm{HbF}$ of similar magnitude in the cells of normal individuals (1.3- to 3.5-fold) and patients with sickle-cell disease (2- to 5 -fold) by hydroxyurea was already reported using a similar erythroid cell culture system (8). It has also been reported that the increase in $\mathrm{HbF}$ levels in erythroid progenitor cells treated with hydroxyurea in vitro is comparable to the rise in peripheral-blood $\mathrm{HbF}$ production (in vivo) after hydroxyurea therapy in patients with sickle-cell anemia (31). Hydroxyurea has little suppressive effect on effective erythropoiesis but increases red blood cell survival (life span, $18.6 \pm 11$ days to $70 \pm 21$ days) as a result of decreased hemolysis in patients with sickle-cell anemia (32), presumably because of reduced intracellular hemoglobin $S$ polymerization resulting from increased intracellular $\mathrm{HbF}$ levels. These selective effects prolong the period during which $\mathrm{HbF}$ rises to reach a therapeutically significant level in peripheral blood of patients with sickle-cell disease and could account for the fact that maximal increases in $\mathrm{HbF}$ levels may take months to occur (33-35). Indeed, maximal increments in F reticulocytes are attained at 10 or 11 days after the start of hydroxyurea treatment in patients with sickle-cell anemia (5, 6), suggesting a rapid effect on the fundamental mechanisms responsible for determining globin gene phenotype. Measurements of $\mathrm{F}$ cells also show maximal increases in 14-21 days (36), confirming the disparity between cellular responses and $\mathrm{HbF}$ levels.

Although it is clear that NO from the NO-donor compounds can directly activate sGC, hydroxyurea could have this effect by at least two separate and independent mechanisms involving NO production or direct interaction between hydroxyurea and sGC. As noted above, hydroxyurea can be oxidized to produce NO in vitro $(14,16)$ and in vivo $(17-20)$. It was also shown, in vitro, that hydroxyurea reacts directly with deoxy-sickle-cell hemoglobin to form methemoglobin and nitrosyl hemoglobin ( $\mathrm{HbNO}$ ). Electron paramagnetic resonance spectroscopy has been used to show 
that the formation of $\mathrm{HbNO}$ involves the specific transfer of $\mathrm{NO}$ from the $-\mathrm{NHOH}$ group of hydroxyurea by a series of intermediate reactions (37), possibly without the formation of free NO. This question is being actively addressed (38).

sGC is a heterodimeric hemoprotein composed of $\alpha$ and $\beta$ subunits with a heme group ligated by a histidine residue of the $\beta 1$ subunit, much like hemoglobin. sGC acts as a target for NO (presumably the free radical $\mathrm{NO} \bullet$ species) by allowing NO to bind directly to the ferrous deoxyheme activating the enzyme (39). In addition, similar to the reaction of hydroxyurea and deoxyhemoglobin to form $\mathrm{HbNO}$, we speculate that hydroxyurea could also directly perform iron nitrosylation on sGC to activate this enzyme system. Thus, hydroxyurea could activate heme proteins, such as sGC, directly or through production of NO.

There are several transcription factors regulated by the NO/cGMP signaling pathway that might participate in hemoglobin switching. The enhancer activity and inducibility of the $\gamma$-globin promoter region are both dependent on the synergistic action of proteins bound to the tandem activator protein 1 (AP-1), which is a heterodimeric protein consisting of $\mathrm{c}$-fos and c-jun subunits $(40,41)$. The NO/cGMP pathway is known to increase both c-fos and c-jun mRNA levels and promotes AP- 1 binding to DNA $(42,43)$, similar to the known effects of hydroxyurea (44). The cellular AP-1 activity is also regulated by the phosphorylation of $\mathrm{c}$-fos and c-jun proteins by the MAPKs. MAPKs are activated by phosphorylation by upstream MAPK kinases (MEKs), which in turn are activated in response to growth factors, cytokines, or various forms of cellular stress (including NO). There have been previous reports of increased phosphorylation of p38 MAPK in human neutrophils (45) and other cell types (46-48) by both NO and cGMP. Hydroxyurea also increases phosphorylation of p38 MAPK in K562 cells (49). In addition, the Sp1binding CCACCC motif is also thought to be critical for high activity of the $\gamma$-globin promoter (50). It was reported that NO increased the activity of the TNF- $\alpha$ promoter by targeting the $\mathrm{Sp} 1$ binding site (51). Thus, NO could potentially affect $\gamma$-globin expression through $\mathrm{Sp} 1$ or related transcription factors, as well as through AP-1.

In summary, our results strongly suggest that $\mathrm{HbF}$ induction by hydroxyurea is mediated by the NOdependent activation of sGC. It is important to note that these effects can also be mediated by other NOdonor compounds. These findings open the door to new therapeutic strategies based on NO delivery by NO donors, arginine salt administration, or increasing NO synthase expression or activity or based on the amplification of NO signal transduction with phosphodiesterase inhibitors. Modulation of this system may allow for the discovery of additive or synergistic regimens that increase responsiveness and reduce morbidity associated with hydroxyurea therapy. Furthermore, individual variations in $\mathrm{NO}$ signal amplification secondary to $\mathrm{NO}$ scavenging or $\mathrm{sGC} /$ phosphodiesterase activities may help explain the well-appreciated variable responsiveness to hydroxyurea treatment.

1. Charache, S., et al. 1995. Effect of hydroxyurea on the frequency of painful crises in sickle cell anemia. Investigators of the Multicenter Study of Hydroxyurea in Sickle Cell Anemia. N. Engl. J. Med. 332:1317-1322.

2. Charache, S. 1997. Mechanism of action of hydroxyurea in the management of sickle cell anemia in adults. Semin. Hematol. 34:15-21.

3. Atweh, G.F., and Schechter, A.N. 2001. Pharmacologic induction of fetal hemoglobin: raising the therapeutic bar in sickle cell disease. Curr. Opin. Hematol. 8:123-130.

4. Letvin, N.L., et al. 1985. Influence of cell cycle phase-specific agents on simian fetal hemoglobin synthesis. J. Clin. Invest. 75:1999-2005.

5. Platt, O.S., et al. 1984. Hydroxyurea enhances fetal hemoglobin production in sickle cell anemia. J. Clin. Invest. 74:652-656.

6. Veith, R., Galanello, R., Papayannopoulou, T., and Stamatoyannopoulos, G. 1985. Stimulation of F-cell production in patients with sickle-cell anemia treated with cytarabine or hydroxyurea. N. Engl. J. Med. 313:1571-1575.

7. Stoeckert, C.J., Jr., and Green, M.B. 1994. Erythropoietin and hydroxyurea can act on early erythroid progenitors from adult human peripheral blood to modulate fetal globin mRNA levels. Exp. Hematol. 22:278-282.

8. Fibach, E., Burke, L.P., Schechter, A.N., Noguchi, C.T., and Rodgers, G.P. 1993. Hydroxyurea increases fetal hemoglobin in cultured erythroid cells derived from normal individuals and patients with sickle cell anemia or beta-thalassemia. Blood. 81:1630-1635.

9. Erard, F., Dean, A., and Schechter, A.N. 1981. Inhibitors of cell division reversibly modify hemoglobin concentration in human erythroleukemia K562 cells. Blood. 58:1236-1239.

10. Xu, J., and Zimmer, D.B. 1998. Differential regulation of A gamma and $\mathrm{G}$ gamma fetal hemoglobin mRNA levels by hydroxyurea and butyrate. Exp. Hematol. 26:265-272.

11. Smith, R.D., Li, J., Noguchi, C.T., and Schechter, A.N. 2000. Quantitative PCR analysis of HbF inducers in primary human adult erythroid cells. Blood. 95:863-869.

12. Yarbro, J.W., Kennedy, B.J., and Barnum, C.P. 1965. Hydroxyurea inhibition of DNA synthesis in ascites tumor. Proc. Natl. Acad. Sci. USA. 53:1033-1035.

13. Krakoff, I.H., Brown, N.C., and Reichard, P. 1968. Inhibition of ribonucleoside diphosphate reductase by hydroxyurea. Cancer Res. 28:1559-1565.

14. Stolze, K., and Nohl, H. 1990. EPR studies on the oxidation of hydroxyurea to paramagnetic compounds by oxyhemoglobin. Biochem. Pharmacol. 40:799-802.

15. Pacelli, R., Taira, J., Cook, J.A., Wink, D.A., and Krishna, M.C. 1996. Hydroxyurea reacts with heme proteins to generate nitric oxide. Lancet. 347:900.

16. Kim-Shapiro, D.B., King, S.B., Bonifant, C.L., Kolibash, C.P., and Ballas, S.K. 1998. Time resolved absorption study of the reaction of hydroxyurea with sickle cell hemoglobin. Biochim. Biophys. Acta. 1380:64-74.

17. Jiang, J., et al. 1997. In vivo production of nitric oxide in rats after administration of hydroxyurea. Mol. Pharmacol. 52:1081-1086.

18. Glover, R.E., Ivy, E.D., Orringer, E.P., Maeda, H., and Mason, R.P. 1999. Detection of nitrosyl hemoglobin in venous blood in the treatment of sickle cell anemia with hydroxyurea. Mol. Pharmacol. 55:1006-1010.

19. Nahavandi, M., Wyche, M.Q., Perlin, E., Tavakkoli, F., and Castro, O. 2000. Nitric oxide metabolites in sickle cell anemia patients after oral administration of hydroxyurea; hemoglobinopathy. Hematology. 5:335-339.

20. Gladwin, M.T., et al. 2002. Nitric oxide donor properties of hydroxyurea in patients with sickle cell disease. Br. J. Haematol. 116:436-444.

21. Lassmann, G., Thelander, L., and Graslund, A. 1992. EPR stopped-flow studies of the reaction of the tyrosyl radical of protein R2 from ribonucleotide reductase with hydroxyurea. Biochem. Biophys. Res. Commun. 188:879-887.

22. Yarbro, J.W. 1992. Mechanism of action of hydroxyurea. Semin. Oncol. 19:1-10.

23. Kwon, N.S., Stuehr, D.J., and Nathan, C.F. 1991. Inhibition of tumor cell ribonucleotide reductase by macrophage-derived nitric oxide. J. Exp. Med. 174:761-767.

24. Lepoivre, M., Flaman, J.M., Bobe, P., Lemaire, G., and Henry, Y. 1994. Quenching of the tyrosyl free radical of ribonucleotide reductase by nitric oxide. Relationship to cytostasis induced in tumor cells by cytotoxic macrophages. J. Biol. Chem. 269:21891-21897.

25. Bundy, R., Marczin, N., Chester, A.H., and Yacoub, M. 1999. Differential 
regulation of DNA synthesis by nitric oxide and hydroxyurea in vascular smooth muscle cells. Am. J. Physiol. 277:H1799-H1807.

26. Ikuta, T., Ausenda, S., and Cappellini, M.D. 2001. Mechanism for fetal globin gene expression: role of the soluble guanylate cyclase-cGMP-dependent protein kinase pathway. Proc. Natl. Acad. Sci. USA. 98:1847-1852.

27. Fibach, E., Manor, D., Oppenheim, A., and Rachmilewitz, E.A. 1989. Proliferation and maturation of human erythroid progenitors in liquid culture. Blood. 73:100-103.

28. Kwan, J.T., Carr, E.C., Bending, M.R., and Barron, J.L. 1990. Determination of carbamylated hemoglobin by high-performance liquid chromatography. Clin. Chem. 36:607-610.

29. Bisse, E., Huaman-Guillen, P., and Wieland, H. 1995. Chromatographic evaluation of minor hemoglobins: clinical significance of hemoglobin A1d, comparison with hemoglobin A1c, and possible interferences. Clin. Chem. 41:658-663.

30. Shami, P.J., and Weinberg, J.B. 1996. Differential effects of nitric oxide on erythroid and myeloid colony growth from CD34+ human bone marrow cells. Blood. 87:977-982.

31. Yang, Y.M., et al. 1997. BFU-E colony growth in response to hydroxyurea: correlation between in vitro and in vivo fetal hemoglobin induction. Am. J. Hematol. 56:252-258.

32. Ballas, S.K., Marcolina, M.J., Dover, G.J., and Barton, F.B. 1999. Erythropoietic activity in patients with sickle cell anaemia before and after treatment with hydroxyurea. Br. J. Haematol. 105:491-496.

33. Goldberg, M.A., et al. 1990. Treatment of sickle cell anemia with hydroxyurea and erythropoietin. N. Engl. J. Med. 323:366-372.

34. Mankad, V.N., Baliga, S., Phillips, K., Shah, A.K., and Yang, Y.M. 1994 Relationship of burst-forming-unit-erythroid progenitors and their DNA-synthesis stage to fetal hemoglobin levels in hydroxyurea-treated patients with sickle cell anemia. Am. J. Hematol. 46:259-263.

35. Rodgers, G.P., et al. 1993. Augmentation by erythropoietin of the fetalhemoglobin response to hydroxyurea in sickle cell disease. N. Engl. J. Med. 328:73-80.

36. Charache, S., Dover, G.J., Moyer, M.A., and Moore, J.W. 1987. Hydroxyurea-induced augmentation of fetal hemoglobin production in patients with sickle cell anemia. Blood. 69:109-116.

37. Kim-Shapiro, D.B., et al. 1999. The reaction of deoxy-sickle cell hemoglobin with hydroxyurea. Biochim. Biophys. Acta. 1428:381-387.

38. Huang, J., et al. 2002. Iron nitrosyl hemoglobin formation from the reactions of hemoglobin and hydroxyurea. Biochemistry. 41:2466-2474.
39. Denninger, J.W., and Marletta, M.A. 1999. Guanylate cyclase and the NO/cGMP signaling pathway. Biochim. Biophys. Acta. 1411:334-350.

40. Moi, P., and Kan, Y.W. 1990. Synergistic enhancement of globin gene expression by activator protein-1-like proteins. Proc. Natl. Acad. Sci. USA. 87:9000-9004.

41. Safaya, S., Ibrahim, A., and Rieder, R.F. 1994. Augmentation of gammaglobin gene promoter activity by carboxylic acids and components of the human beta-globin locus control region. Blood. 84:3929-3935.

42. Haby, C., Lisovoski, F., Aunis, D., and Zwiller, J. 1994. Stimulation of the cyclic GMP pathway by NO induces expression of the immediate early genes c-fos and junB in PC12 cells. J. Neurochem. 62:496-501.

43. Idriss, S.D., et al. 1999. Nitric oxide regulation of gene transcription via soluble guanylate cyclase and type I cGMP-dependent protein kinase. J. Biol. Chem. 274:9489-9493.

44. Adunyah, S.E., Chander, R., Barner, V.K., and Cooper, R.S. 1995. Regulation of c-jun mRNA expression by hydroxyurea in human K562 cells during erythroid differentiation. Biochim. Biophys. Acta. 1263:123-132.

45. Browning, D.D., Windes, N.D., and Ye, R.D. 1999. Activation of p38 mitogen-activated protein kinase by lipopolysaccharide in human neutrophils requires nitric oxide-dependent cGMP accumulation. J. Biol. Chem. 274:537-542.

46. Browning, D.D., McShane, M.P., Marty, C., and Ye, R.D. 2000. Nitric oxide activation of p38 mitogen-activated protein kinase in $293 \mathrm{~T}$ fibroblasts requires cGMP-dependent protein kinase. J. Biol. Chem. 275:2811-2816.

47. Kim, S.O., Xu, Y., Katz, S., and Pelech, S. 2000. Cyclic GMP-dependent and -independent regulation of MAP kinases by sodium nitroprusside in isolated cardiomyocytes. Biochim. Biophys. Acta. 1496:277-284.

48. Chen, K., and Maines, M.D. 2000. Nitric oxide induces heme oxygenase1 via mitogen-activated protein kinases ERK and p38. Cell. Mol. Biol. (Noisy-le-grand). 46:609-617.

49. Park, J.I., Choi, H.S., Jeong, J.S., Han, J.Y., and Kim, I.H. 2001. Involvement of p38 kinase in hydroxyurea-induced differentiation of K562 cells. Cell Growth Differ. 12:481-486.

50. Fischer, K.D., Haese, A., and Nowock, J. 1993. Cooperation of GATA-1 and $\mathrm{Sp} 1$ can result in synergistic transcriptional activation or interference. J. Biol. Chem. 268:23915-23923.

51. Wang, S., Wang, W., Wesley, R.A., and Danner, R.L. 1999. A Sp1 binding site of the tumor necrosis factor alpha promoter functions as a nitric oxide response element. J. Biol. Chem. 274:33190-33193. 